\title{
Comparison of the diagnostic accuracy of different image processing algorithms in the diagnosis of jawbone defects
}

\author{
Farzaneh Mirhoseini $^{1}$ (D), Mehdi Tabrizizadeh ${ }^{2}$ (D), Azadeh Falah-Yakhdani ${ }^{3}$, \\ Amin Ansarinia ${ }^{4}$, Monireh Sadoughi ${ }^{5}$ \\ ${ }^{1}$ Department of Oral and Maxillofacial Radiology, School of Dentistry, Shahid Sadoughi University of Medical Sciences, Yazd, Iran \\ ${ }^{2}$ Department of Endodontics, School of Dentistry, Shahid Sadoughi University of Medical Sciences, Yazd, Iran \\ ${ }^{3}$ General Dentist, Yazd, Iran. \\ ${ }^{4}$ School of Dentistry, Shahid Sadoughi University of Medical Sciences, Yazd, Iran \\ ${ }^{5}$ Corresponding author; Department of Operative Dentistry, School of Dentistry, Shahid Sadoughi University of Medical Sciences, \\ Private Practice, Yazd, Iran \\ Tel:03536255881_E-mail:sadoughi_monireh@yahoo.com
}

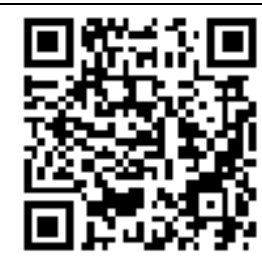

Citation Mirhoseini F, Tabrizizadeh M, Falah-Yakhdani A, Ansarinia A, Sadoughi M. [Comparison of the diagnostic accuracy of different image processing algorithms in the diagnosis of jawbone defects]. J Birjand Univ Med Sci. 2019; 26(1):54-63. [Persian]

DOI http://doi.org/10.32592/JBirjandUnivMedSci.2019.26.1.106

Received: July 11, 2018

Accepted: December 11, 2018

\begin{abstract}
ABSRRACT
Background and Aim: Intra-bone lesions are common in lesions, among them periapical lesions have a higher incidence. Todays, all direct digital imaging systems provide various types of image processing techniques. The purpose of this study is to investigate the effects of different digital image processing techniques on the diagnosis of bony defects.

Materials and Methods: In this experimental study, 50 sheep inferior half-jawbones were used. Lesions were created by round bars with numbers $1_{/ 4}, 1_{/ 2}, 1,2$ and 4 . Digital images were obtained by edge enhance, sharpening, invert gray scale processing method and unprocessed investigated by two radiologists and in case of disagreement them observers by third observer. The method of recording the results was definitive diagnosis of lesion number 1, misdiagnosis number 2 and possible diagnosis number 3 . The results were analyzed by chi-square and Fisher's exact tests.
\end{abstract}

Results: Percent of diagnostic sensitivity in unprocessed Images $(71.8 \%)$ and images processed with Sharpen filter $(71.4 \%)$ were significantly higher than images processed with invert grayscale $(68.5 \%)$ and edge Enhancer $(53 \%) .(\mathrm{p}<0.001)$

Conclusion: To detect bone lesions, unprocessed and processed digital images with Sharpen filters have higher diagnostic accuracy.

Key Words: Digital Radiography; Image Processing; Bony Defect 


\title{
مقايسه دقت تشخيصى الكوريتمهاى مختلف ير دازش تصوير در تشخيص ضايعات استخوانى فك
}

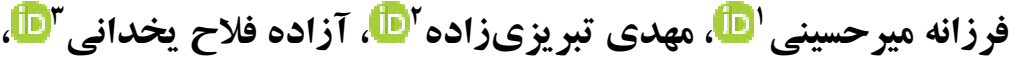

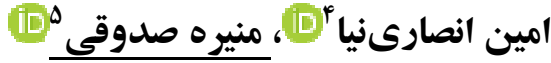

\begin{abstract}
جكکبه
زمينه و هدف: ضايعات داخل استخوانى، از ضايعات شايع هستند كه در بين آنها ضايعات يرىاييكال شيوع بالاترى دارند. امروزه تمام

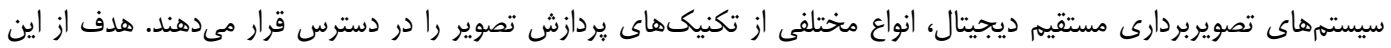

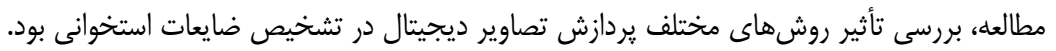

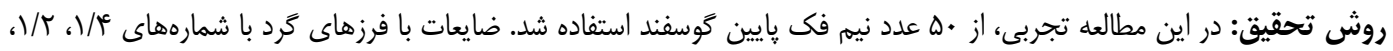

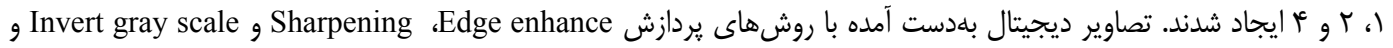
به شكل بردازشنشده، توسط دو نفر راديولوزيست و در صورت عدم توافق دو مشاهدهَّر، توسط مشاهده

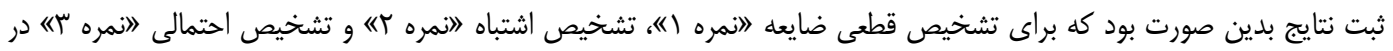

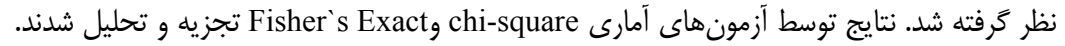

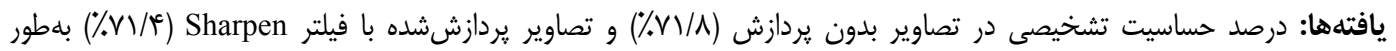

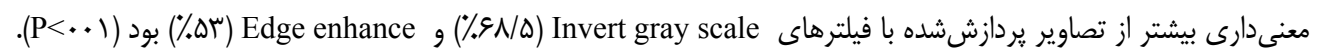

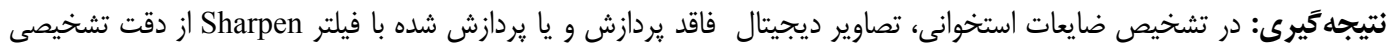
بالاترى برخوردارند.

$$
\begin{aligned}
& \text { وازههاى كليدى: راديوكر افى ديجيتال؛ بردازش تصوير؛ ضايعه استخوانى }
\end{aligned}
$$

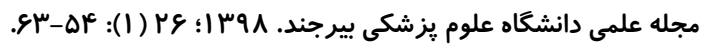

$$
\begin{aligned}
& \text { دريافت: •r/F/ }
\end{aligned}
$$

\footnotetext{
'كروه أموزشى راديولوزى دهان و فكى و صورت، دانشكده دندانيزشكى، دانشكاه علوم يزشكى و خدمات بهداشتى و درمانى شهيد صدوقى يزد، يزد، ايران

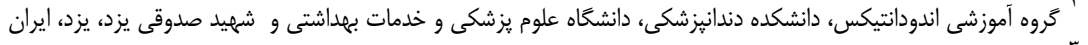

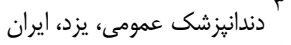

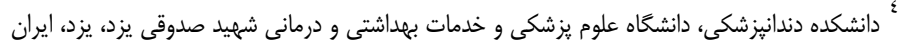

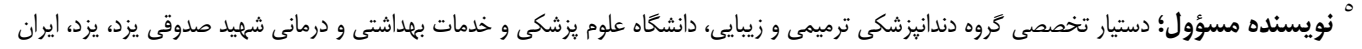

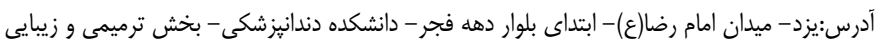

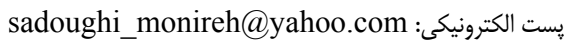

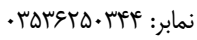


متداولترين روش براى بررسى استخوان پرىاييكال است

(ᄉ)

افزايش دقت سيستههاى راديوگرافى براى تشخيص سريعتر ضايعات موجود در فى نياز است. بدينمنظور

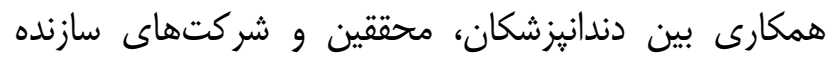

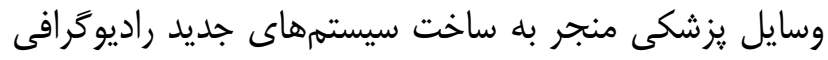

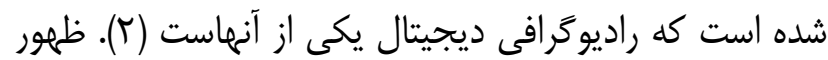
تصويربردارى ديجيتال، تحوّلى در راديوكرافى ايجاد كرد (V).

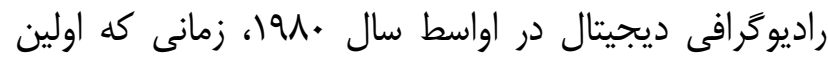

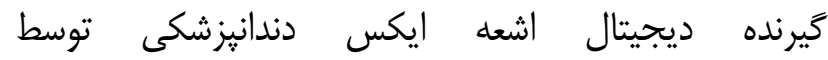
Francis Mine

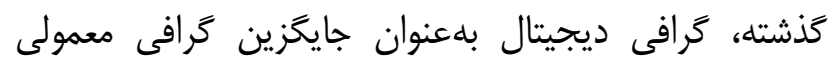
مورد قبول واقع شده است. اين جايخزينى سبب تغييراتى در درئه

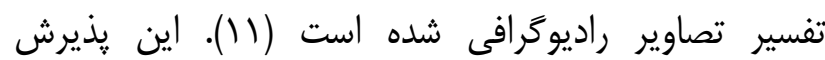

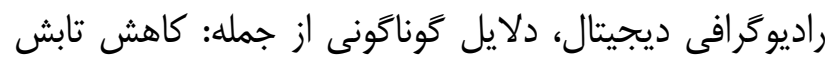

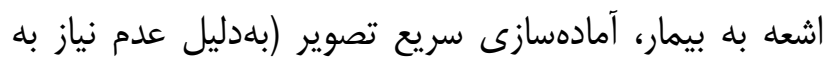

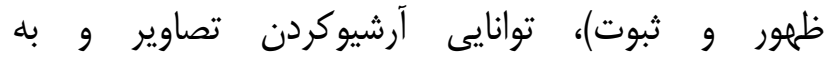
اشتراك گذاشتن آنها و توانايى دستكارى تصاوير (ه) دارد.

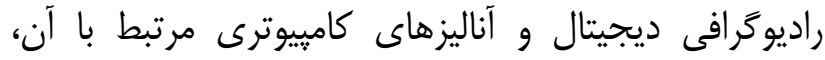

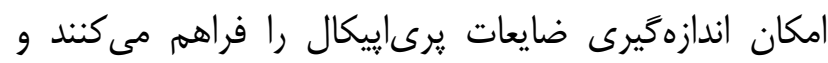

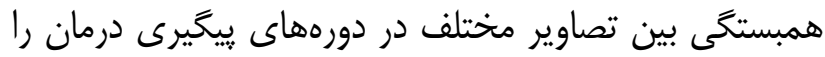

$$
\text { فراهم مى آورند (9). }
$$

تصويربردارى ديجيتال قابليت يردازش تصوير با امكان يردازش كمى و كيفى تراكم استخوان، بهبود دانسيته، كنتراست، وارونگى درجه خاكسترى، رنخ كاذب و سلبعدى كاذب را فراهم مى كند (·) (1). يردازش تصوير يعنى هر روشى كه در جهت بهبود، بازسازى و تجزيه و تحليل تصاوير به كار رود و يا هر روشى كه سبب تغيير در تصاوير ديجيتال

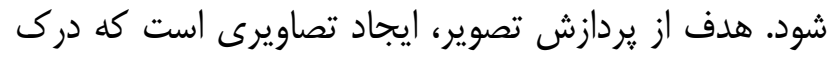

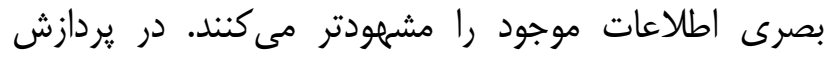
تصوير براى اهداف مختلف، تنظيمات متفاوتى روى

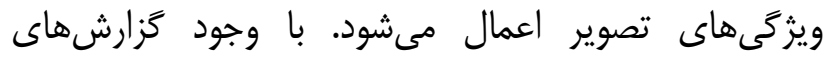

مقلدمه

تغيير تراكم استخوان، بارزترين ويزگى ييشرفت يا ازبينرفتن التهاب يرىاييكال است ((). تشخيص زودهنگام ضايعه مىتواند باعث تسريع شروع درمان و جلوكيرى از

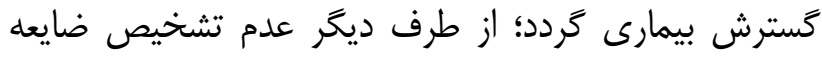

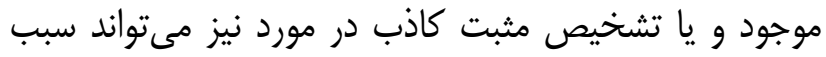

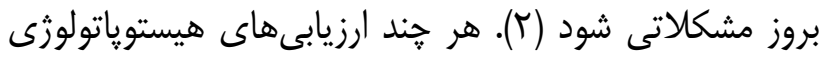

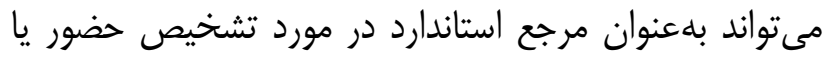

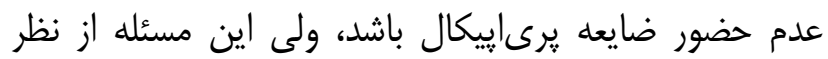

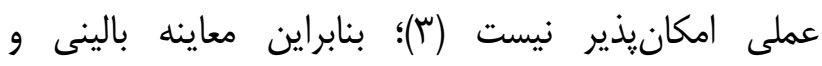

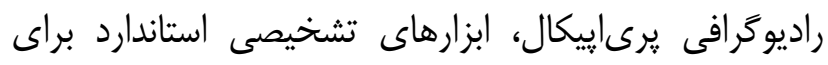

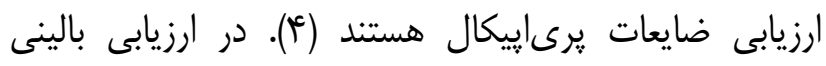

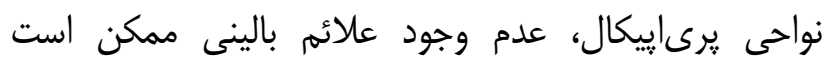

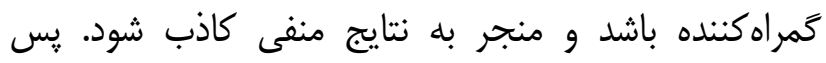

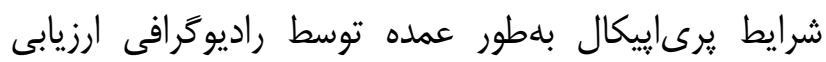

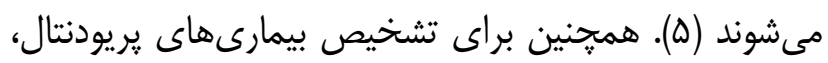

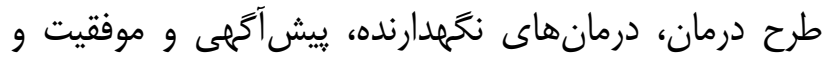
شكست درمان بيمارىهاى يريودنتال و بررسى ناحيه توسط دران راديوگرافى يرىاييكال ضرورى است (V، $\&$ ()).

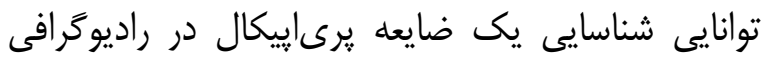
نهتنها به اندازه ضايعه بستخى دارد، بلكه به درگيرى استخوان

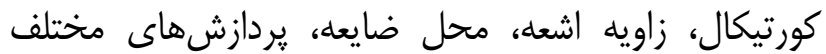
راديوگرافى و تركيب بافتهاى مينراليزه نيز بستخى دارد (م)، ז). البته راديوگرافىها يكسرى محدوديتهايى دارند كه محدوديت آنها بهدليل شرايط آناتوميك، اشكالات هندسى و دوبعدىبودن تصاوير است (9). محدوديت ديخرى كه در ارتباط با تصاوير راديوگرافى وجود دارد، اين است كه ضايعات استخوانى زمانى در تصاوير راديوگرافى قابل مشاهده هستند كه تحليل در استخوان كورتيكال اتفاق بيفتد (^) و يا در راديوگرافى معمولى، حدود ·سردصد تغيير در مواد معدنى براى

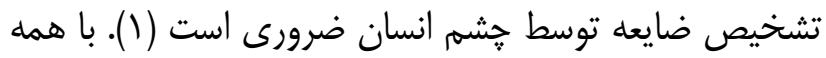
محدوديتها، باز هم تصاوير راديوگرافى داخل دهانى 
بود كه تنها فرد عمل كننده از ترتيب و فاصله آنها مطلع بود. استخوانهاى فى يايين براى بازسازى بافت نرم، توسط

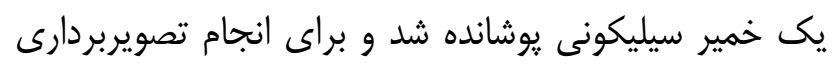

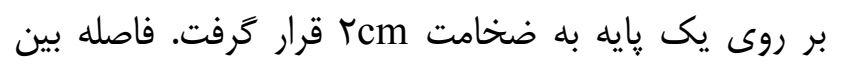

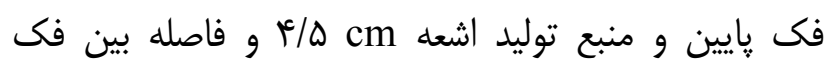

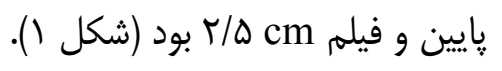
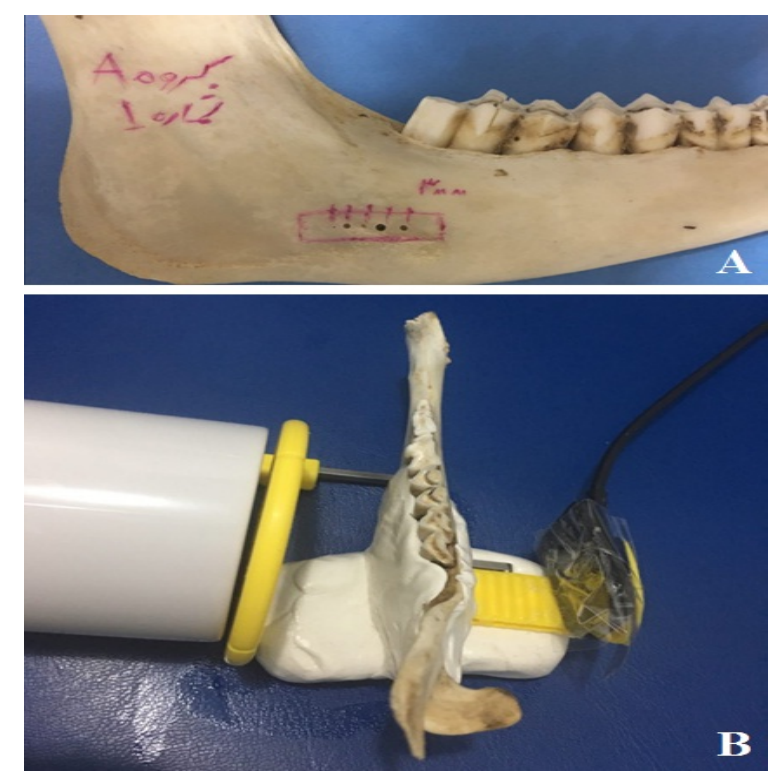

شكل (- A ) ضايعات ايجادشده در نيم فك بايين، B) نحوه تحرفتن تصاوير ديجيتال از نيم فك يايين

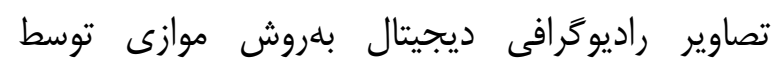

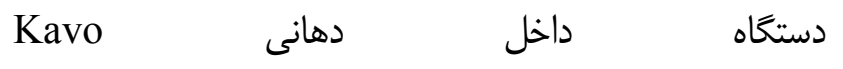
(Kavodental, Bibrach, Germany)

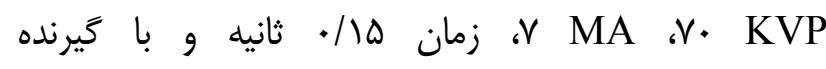
EZ SENSOR 1/5 (Watech, Korea)

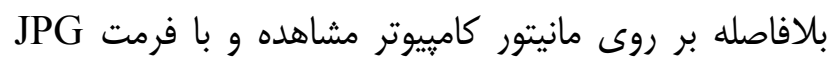

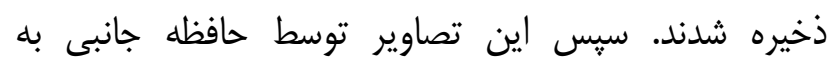

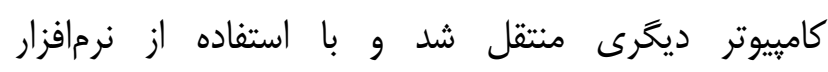
Sharpening Edge enhance يردازش إنهاى IMAGE J و Invert gray scale بر روى راديوكرافى ها انجام شد
متفاوتى كه در مورد وضوح تصاوير ديجيتالى وجود دارد، ديجيتالىشدن، فرصتى براى يردازش تصوير ايجاد مى كند كه ونه مى تواند كيفيت تصوير را بهبود بخشد (• (1).

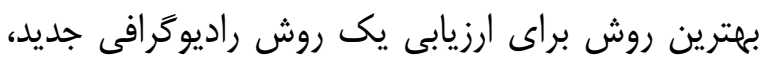

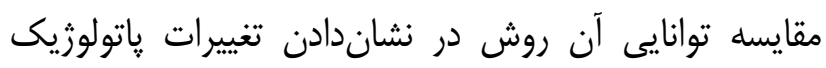

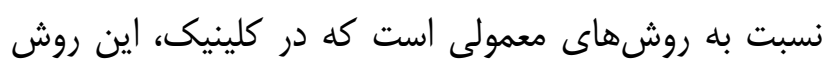

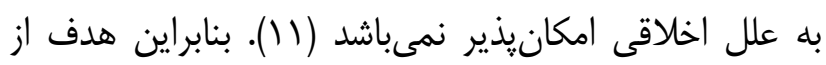

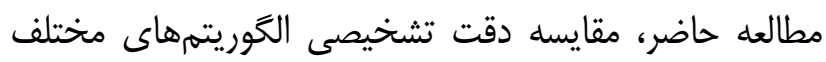

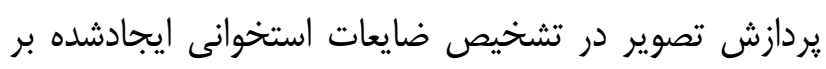

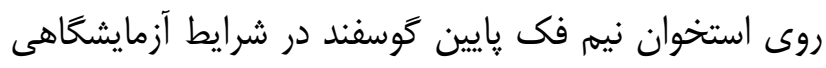

\section{روش تحقيق}

اين مطالعه تجربى بلهورت in vitro بر روى •ه مد عدد

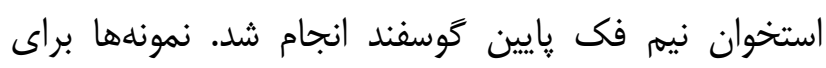

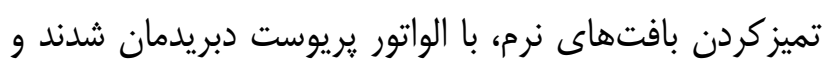

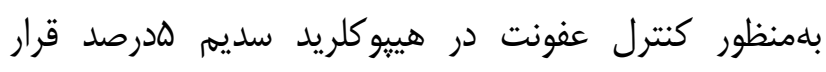
كرفتند. براى ايجاد ضايعات استخوانى، در قسمت خلفى استخوان نيم فى پايين گوسفند توسط فرز گرد توربين با شمارههاى

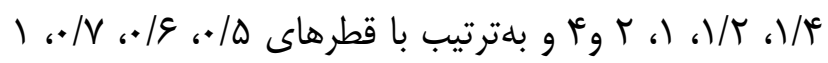

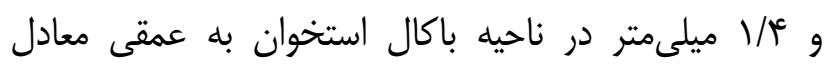

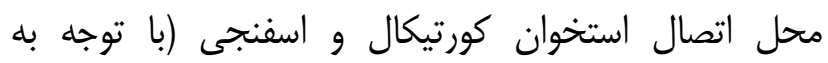
ضخامت استخوان كورتيكال كه از محل مقطع استخوان أصنان مشخص و قابل اندازمكيرى بود و احساس تغييير تراكم استخوان در حين تراش توسط فرز)، حفراتى به قطرهاى معادل قطر فرزهاى بيانشده و در راستاى يك خط تراش مستقيم

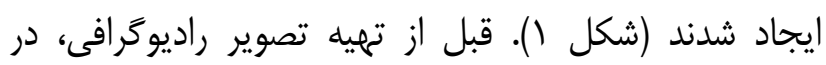

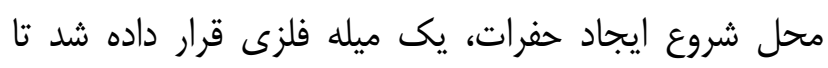

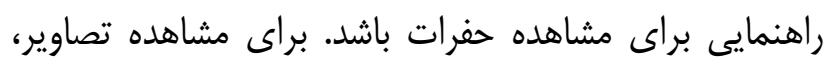

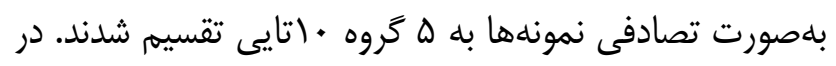

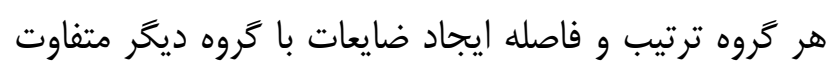



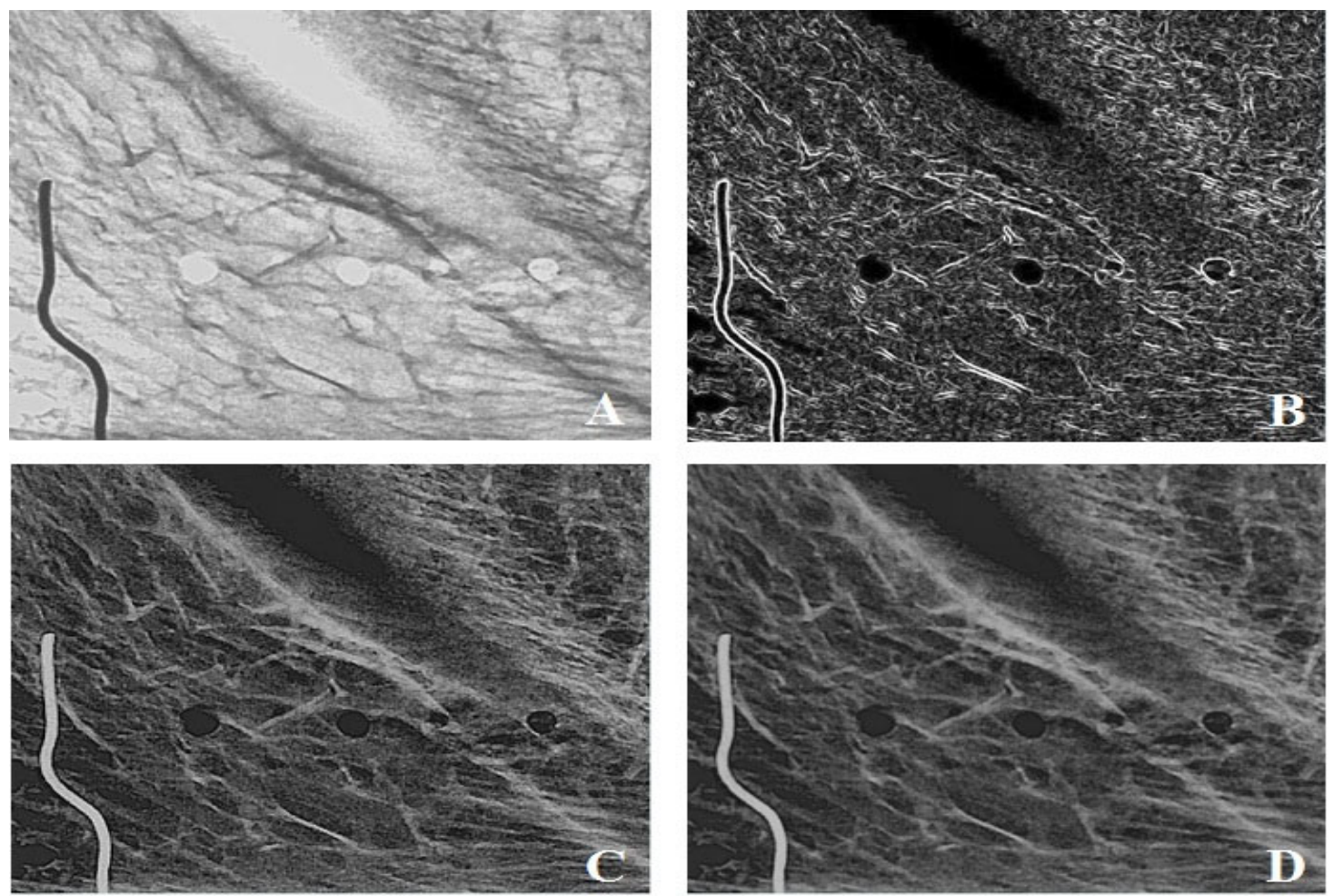

شكل r- تصوير راديوكر افى ضايعات ايجادشده در استخوان با اعمال الكوريتمهاى: Sharp (C Edge (B Invert (A و D بدون تغيير

ضريب Inter Class Correlation) ICC) استفاده شد. مقدار اين ضريب اخر در محدوده (-) قرار گيرد، يعنى ياسخ مشاهده كنندكان بر خلاف يكديگر است؛ اگر در محدوده (•) قرار گيرد، يعنى ياسخها هيج ربطى با يكديگر ندارند و اگر در محدوده (+) قرار گيرد، يعنى ياسخها با يكديخر توافق دارند. هر جه اين عدد بيشتر باشد، نشاندهنده توافق بهتر مشاهده كنندكان است

دادههاى به دست آمده، يس از ورود به نرمافزار

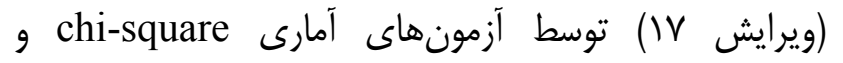
Fisher's exact قرار گرفتند. اين مقاله برگرفته از ياياننامه دانشجويى بـ شماره NTd مصوب شوراى يزوهشى دانشكده دندانيزشكى شهيد صدوقى يزد مىباشد. همجنين تأييديه كميته اخلاق در

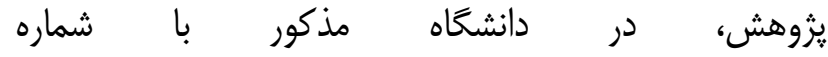
IR.SSU.REC.1396.45 براى اين مطالعه اخذ گرديد.
با احتساب راديوگرافى اوليه، در مجموع ع راديوگرافى (در كل · ·. راديوگرافى) از هر ناحيه إييكال وجود داشت. ارزيابى Sumsung ب اينج $19 \quad$ مانيتور

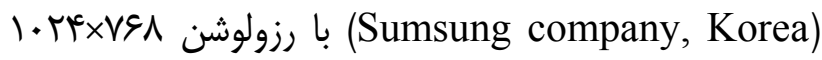
ييكسل، تحت شرايط استاندارد و بدون دستكارى كنتراست و روشنايى، توسط دو نفر مشاهده كننده و در مواردى كه بين دو مشاهدهر توافق وجود نداشت، توسط مشاهدهر سوم مورد بررسى قرار گرفتند. لازم به ذكر است كه تصاوير بلصورت تصادفى و بلدون آكاهى مشاهده كنندًان از ترتيب و فاصله ضايعات نمايش داده شدند. نظر مشاهده كنندهان در مورد وجود يا عدم وجود ضايعه استخوانى با مقياسهاى () ضايعه قطعاً وجود دارد، r) ضايعه قطعاً وجود ندارد و ب) در مر مورد وجود يا عدم وجود ضايعه اطمينان نيست، در جـكليست ثبت شدند و در صورت عدم تطابق گِاسخ دو مشاهدهگر، از پاسخ مشاهدهر سوم بلعنوان تشخيص نهايى استفاده شد. در اين مطالعه براى بررسى توافق مشاهده كنندكان، از 


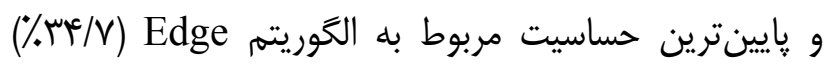

يافتهها

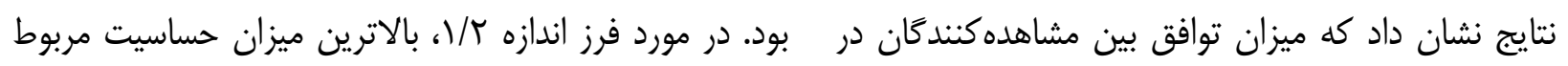

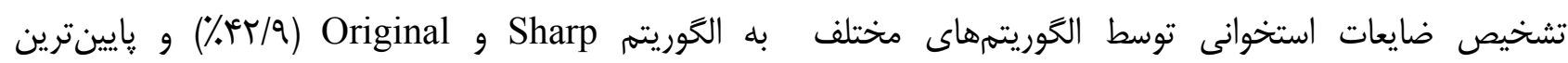

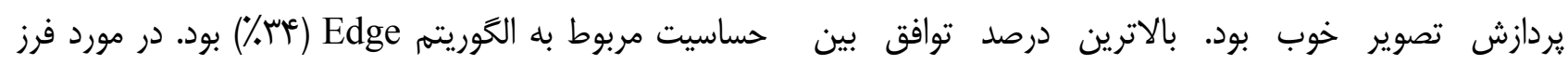

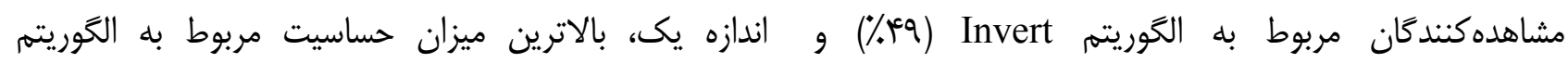

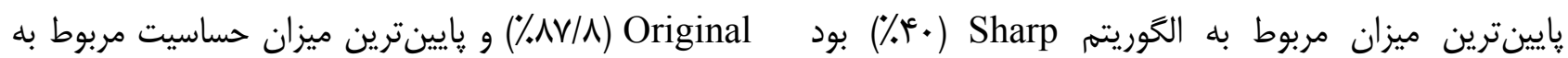

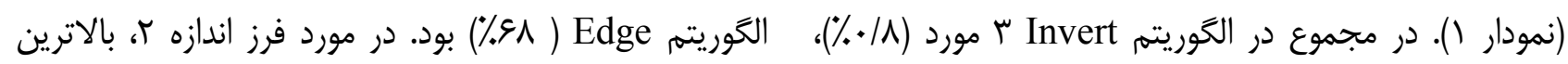

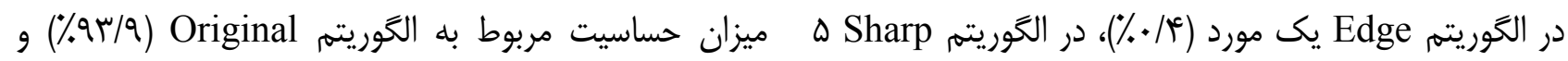

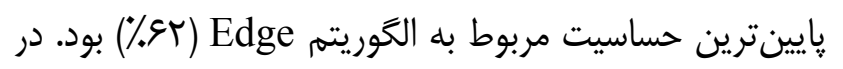

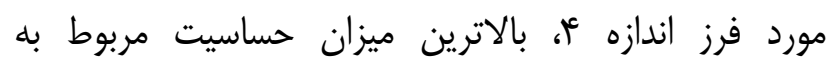

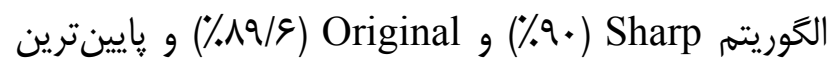

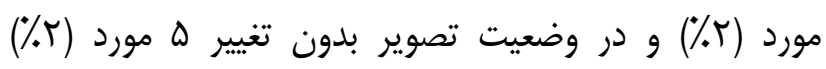
نتيجه مشخص نبود. حساسيت مربوط به الخوريتم Edge (rو٪\%) بود (جدول ()).

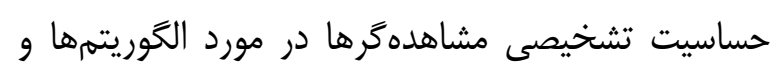

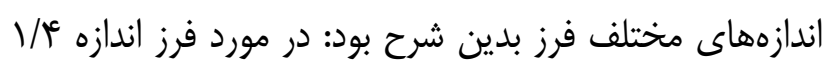

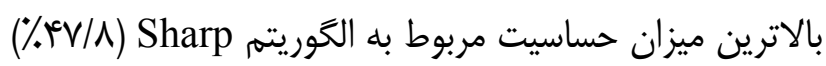

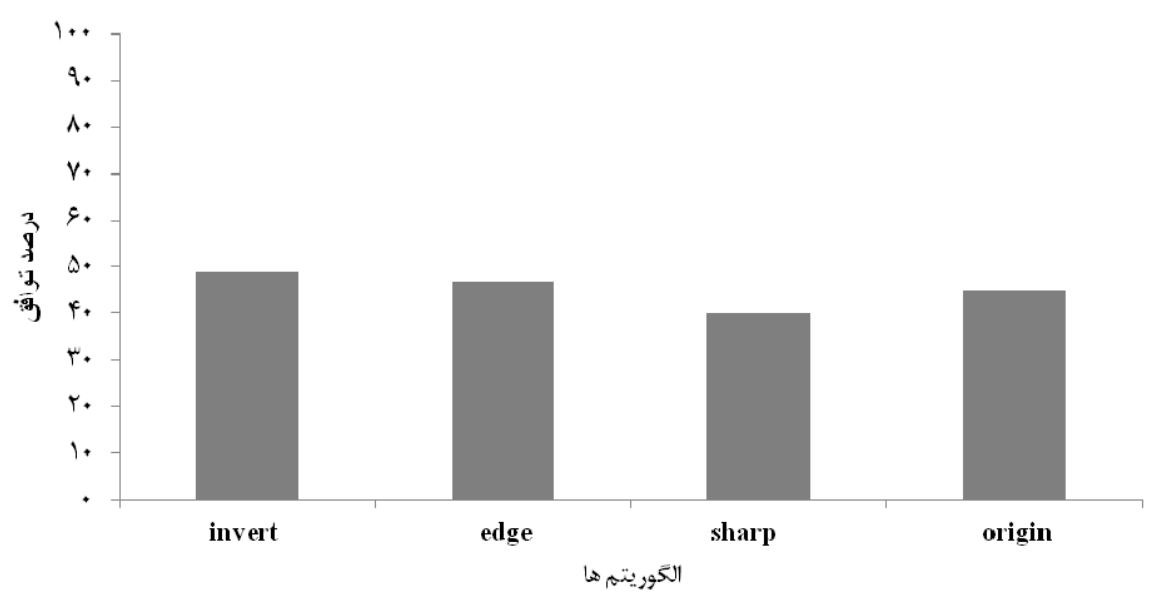

نمودار ا - درصد توافق بين پاسخ مشاهده كنندكًان به متغيرها

جدول ا - مقايسه درصد حساسيت تشخيصى الخَوريتمهاى مختلف يردازش تصوير در اندازههاى مختلف فرز

\begin{tabular}{|c|c|c|c|c|}
\hline \multicolumn{4}{|c|}{ الخوريته } & \multirow{2}{*}{ اندازه فرز } \\
\hline Origin & Sharp & Edge & Invert & \\
\hline$\%$ & $\%+v / q$ & $\% m E / V$ & $\%$ & $\frac{1}{7}$ \\
\hline$\%$ FT/q & $\%$ cr/q & $\%$ me & $\%+c \cdot 1 \Lambda$ & $\frac{1}{r}$ \\
\hline$\% \wedge \mathrm{V} / \wedge$ & $\%$ & $\% 99$ & $\%$ \% & 1 \\
\hline$\% 94 / 9$ & $\% 91 / V$ & $\% \& \wedge$ & $\% \wedge \mathrm{V} / \wedge$ & r \\
\hline$\%$ ११/द & $\% 9$. & $\%$ \% & $\%$ & f \\
\hline$\% \vee / \wedge$ & $\% v / s^{c}$ & س.מ. & $\% \& N / \Delta$ & ميانگين درصد \\
\hline
\end{tabular}


Colour coding تصويربردارى ديجيتال معمولى و سيستم خوب ززارش كردند، همسو مىباشد. در اين مطالعه، حساسيت تشخيصى در وضعيت تصوير معردير بدون تغيير (Original) و در الكوريتم Sharp، با نتايج حاصل از مطالعه Scaf و همكاران (V.V. (Y) كه به مطالعه

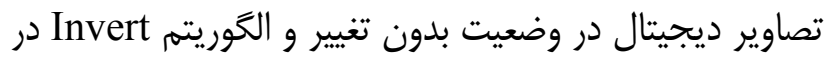

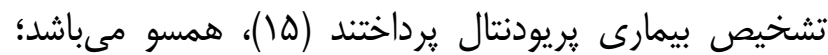

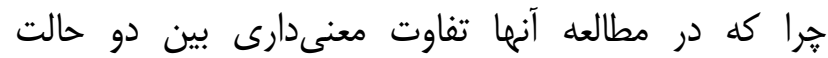

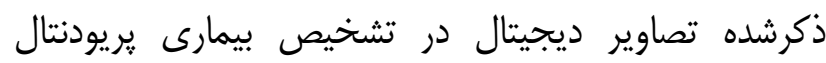

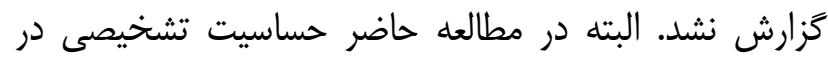

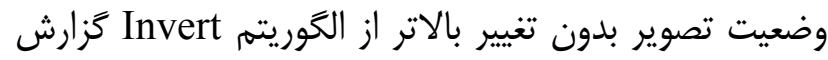

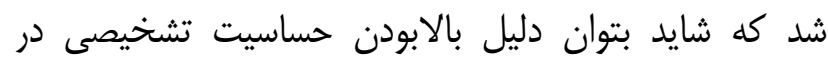

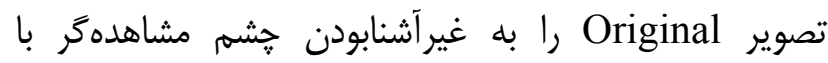
تصاوير يردازش شده نسبت داد.

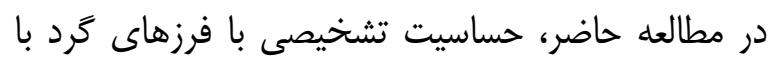

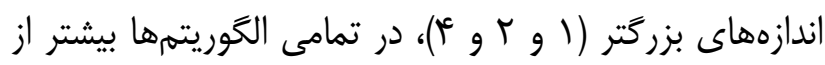

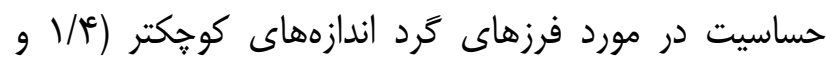

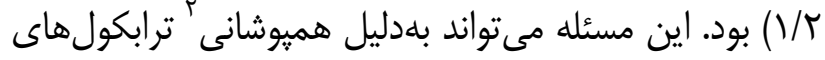

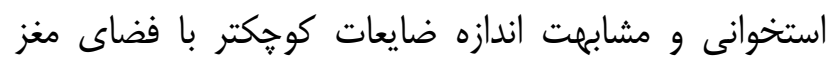
استخوانى باشد كه مىتواند باعث مخفى شدن ضايعات التهات شود.

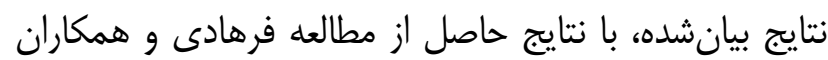
كه دقت تشخيصى راديوگرافى ديجيتال يرىاييكال را در مورد فايلهاى كوخجكتر اندودنتيك در نواحى نزديكتر به ديه نوك ريشه كمتر از فايلهاى بزركتر كزارش كردند (عا)، مشابه مىباشد. Pati و همكاران نيز در مطالعه خود حساسيت تشخيصى بالاترى را در مورد فرزهاى اندازه بزرگتر در مقايسه با فرزهاى با اندازههاى كوجىتر گزارش كردند (II) كه نتايج اين مطالعه نيز با نتايج مطالعه حاضر همسو مىباشد.

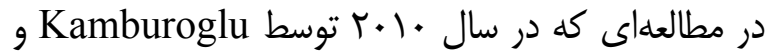
همكاران بر روى سو دندان يرمولر كشيدهشده منديبل انجام شد، حضور يا عدم حضور شكستخى عمودى ريشه، توسط

\footnotetext{
${ }^{2}$ Superimpose
}

Original به طور كلى حساسيت تشخيصى در وضعيت

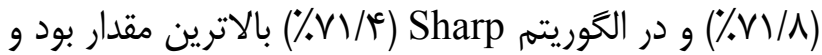
كمترين حساسيت مربوط به الخوريتم Edge (سهه٪) بود. همجنين در تمامى الكوريتهها حساسيت تشخيصى ضايعات ايجادشده با فرز اندازه r بيشترين ميزان و در رتبه دوم و با فاصله اندك فرز اندازه ז بالاترين مقادير را داشت؛ فرز اندازه 1/ 1/ نيز كمترين ميزان حساسيت را داشت. تمامى موارد تفاوت الكُوريتمهاى مختلف و اندازههاى متفاوت فرز درين حساسيت تشخيصى از لحاظ آمارى معنىدار بود ( ( +. (P<).

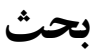

تشخيص زودرس يك ضايعه مىتواند باعث تسريع شروع

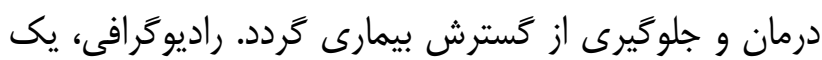

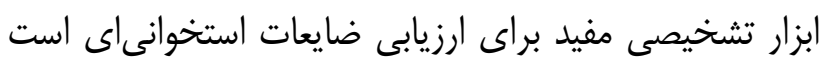

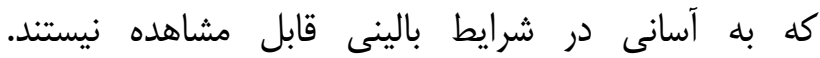

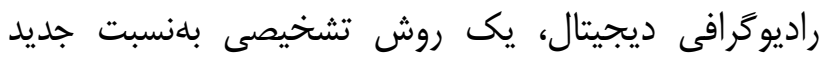

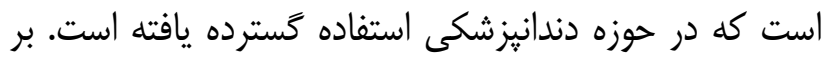
طبق نظر بسيارى از محققان، راديوگرافى ديجيتال در مقايسه

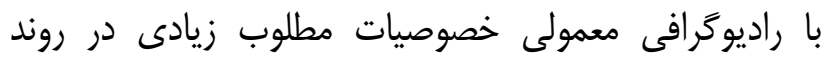
تشخيص دارد. يكى از اين خصوصيات مطلوب، قابليت استفاده از فيلترهاى بهبود تصوير متفاوت' است كه به إنه تشخيص دقيقتر در دندانيزشكى كمك مى كند (سا، ז) (I). قابل اعتمادترين روش براى ارزيابى يك سيسته تصويربردارى، مقايسه توانايى آن در تشخيص ضايعات ياتولوزيك با شرايط واقعى است. در شرايط كلينيكى، اين امر به دلايل اخلاقى امكانيذير نيست (fأ). در مطالعه حاضر توافق بين مشاهدهرها كه توسط ضريب ICC سنجيده شد، در مورد الخوريتههاى مختلف

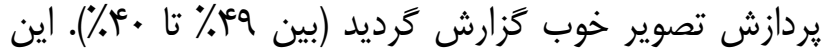
نتيجه با نتايج حاصل از مطالعه Pati و همكاران (II) كه توافق بين مشاهدهرها را در مورد روشهاى مختلف

\footnotetext{
${ }^{1}$ Enhancement filters
} 
ضايعات استخوانى بيشتر مىشد، احتمال تشخيص ضايعه

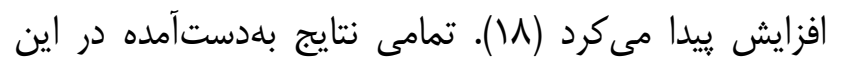
مطالعه با نتايج مطالعه حاضر همرسو مىباشد.

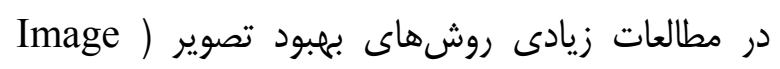
(enhancement techniques

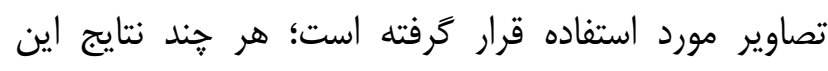

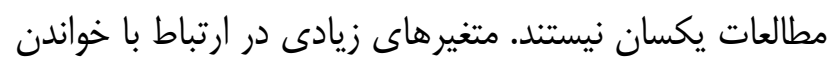

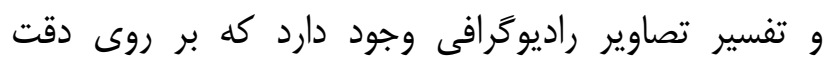
تشخيصى ضايعات استخوانى اثر دارند. Vander stelt

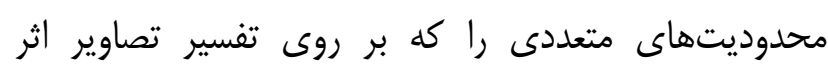

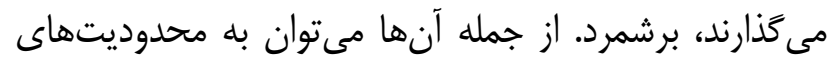

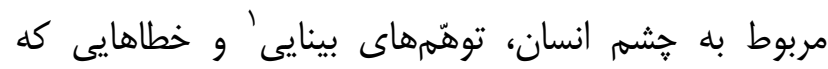

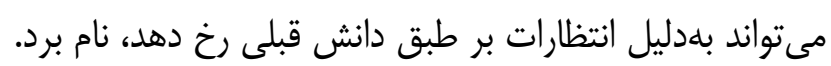

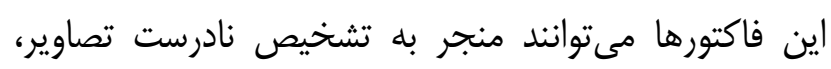
حتى با وجود تلاش براى تصادفى كردن تصاوير ارئهشده شوند

\section{نتيجه Fيرى}

بر اساس نتايج مطالعه ميتوان كفت كه يردازش در تصاوير

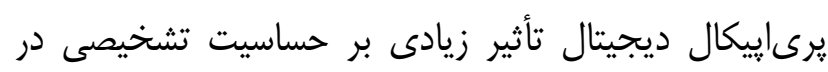

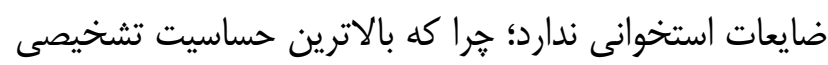

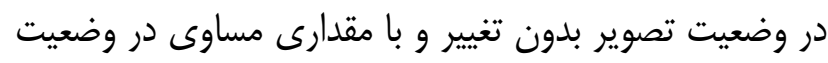

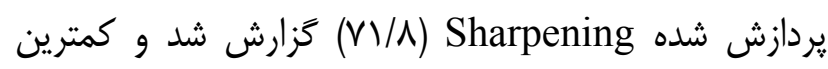
حساسيت تشخيصى در وضعيت يردازششده Edge (سهد\%) مشاهده شد. حساسيت تشخيصى در تمامى الخَوريتهها در

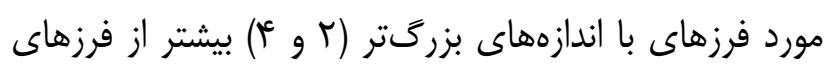

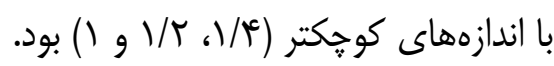

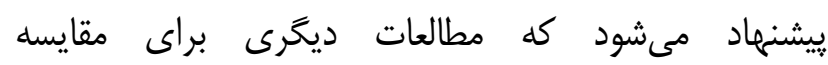

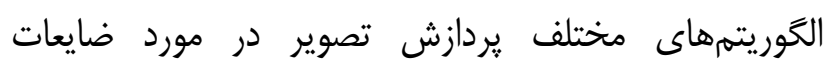

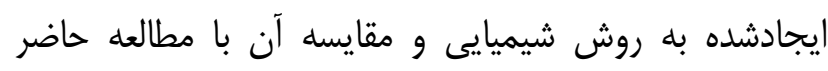

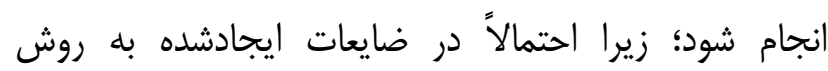

\footnotetext{
${ }^{1}$ Optical illusions
}

روشهاى مختلف بهبود تصوير بهارگرفتهشده در

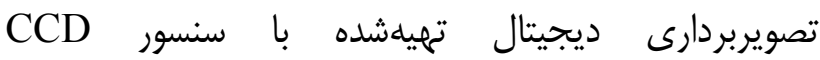
كه شامل الخوريتمهاى (Charge coupled device) 9 Reverse contrast ‘Zoom-in sharpening Pseudo-3D

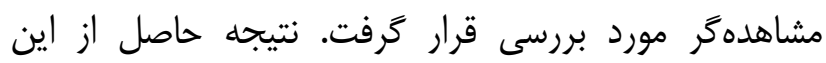

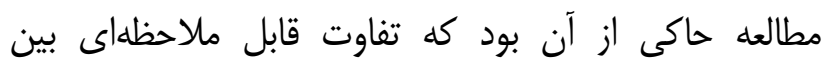

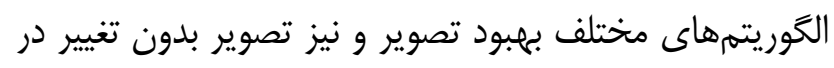
تشخيص شكستخى عمودى ريشه وجود ندارد. در اين مطالعه

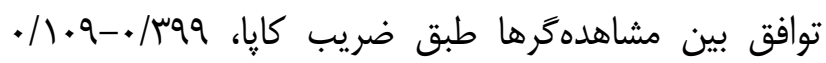

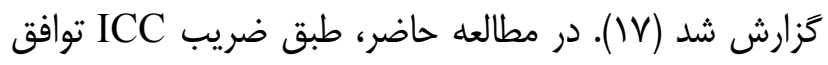

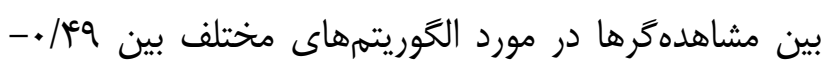

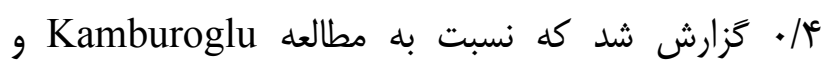

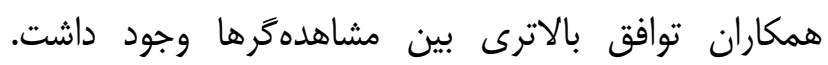

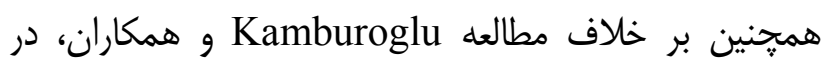
مطالعه حاضر تفاوت بين الخُوريتمهاى مختلف يردازش مار تصوير

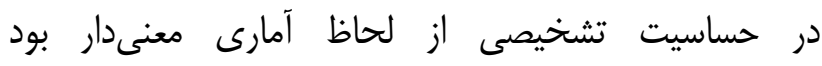
كه اين تفاوت را مىتوان به تفاوت در روش كار دو مطالعه نسبت داد.

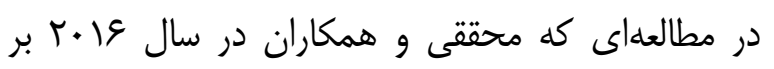

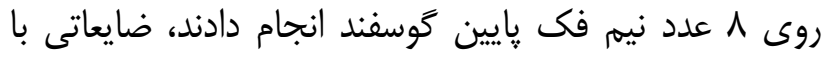

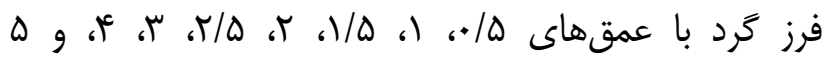
ميلىمتر ايجاد شدند. تصاوير ديجيتال بلددستآمده از 1 نيم

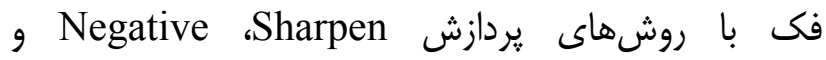
3D Embossed

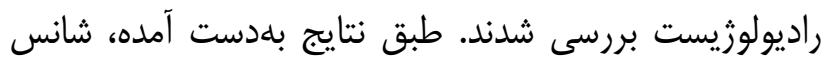

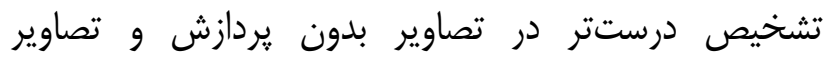

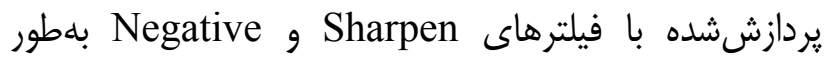

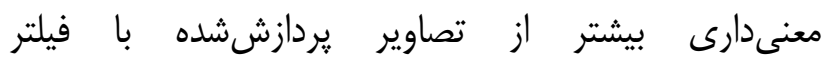

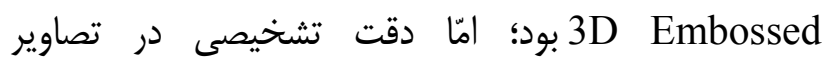
يردازشنشده و تصاوير يردازششده با فيلترهاى Sharpen

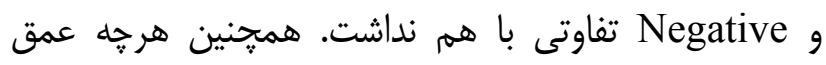


1- Soğur E, Baksı BG, Gröndahl HG, Sen BH. Pixel intensity and fractal dimension of periapical lesions visually indiscernible in radiographs. J Endod. 2013; 39(1): 16-9.

2- Tabrizizadeh M, Abrisham SM, Yazdani E. The accuracy comparison of direct digital radiography (DDR) and conventional radiography in detecting chemically created lesions. J Dent Sch Shahid Beheshti Univ Med Sci. 2011; 29(1): 55-61.[Persian]

3- Davies A, Mannocci F, Mitchell P, Andiappan M, Patel S. The detection of periapical pathoses in root filled teeth using single and parallax periapical radiographs versus cone beam computed tomography - a clinical study. Int Endod J. 2015; 48(6): 582-92.

4- Shahbazian M, Vandewoude C, Wyatt J, Jacobs R. Comparative assessment of periapical radiography and CBCT imaging for radiodiagnostics in the posterior maxilla. Odontology. 2015; 103(1): 97-104.

5- Tarcin B, Gumru B, Iriboz E, Turkaydin DE, Ovecoglu HS. Radiologic Assessment of Periapical Health: Comparison of 3 Different Index Systems. J Endod. 2015; 41(11): 1834-8.

6- Aoki EM, Abdala-Junior R, de Oliveira JX, Arita ES, Cortes AR. Reliability and Reproducibility of Manual and Automated Volumetric Measurements of Periapical Lesions. J Endod. 2015; 41(9): 1555-9.

7- ShamlouMahmoudi N, Safi Y, Ansari H, Afshari S. Comparison of Digital and Conventional Radiography In Evaluating Horizontal Alveolar Bone Loss. Zahedan J Res Med Sci. 2009; 11(2): 49-56.[Persian]

8- Jorge EG, Tanomaru-Filho M, Guerreiro-Tanomaru JM, Reis JM, Spin-Neto R, Goncalves M. Periapical repair following endodontic surgery: two- and three-dimensional imaging evaluation methods. Braz Dent J. 2015; 26(1): 6974.

9- Miguens SA Jr, Veeck EB, Fontanella VR, da Costa NP. A comparison between panoramic digital and digitized images to detect simulated periapical lesions using radiographic subtraction. J Endod. 2008; 34(12): 1500-3.

10- Malleshi SN, Mahima VG, Raina A, Patil K. A Subjective Assessment of Perceived Clarity of Indirect Digital Images and Processed Digital Images with Conventional Intra-oral Periapical Radiographs. J Clin Diagn Res. 2013; 7(8): 1793-6.

11- Pati AR, Mubeen VK, Bhuyan SK, PAniGRAhi RG, PRiyADARShini SR, MiSRA S, et al. A comparative study on diagnostic accuracy of colour coded digital images, direct digital images and conventional radiographs for periapical lesions - an in vitro study. J Clin Diagn Res. 2014; 8(11): ZC55-9.

12- Li G, Engström PE, Nasström K, Lü ZY, Sanderink G, Welander U. Marginal bone levels measured in film and digital radiographs corrected for attenuation and visual response: an in vivo study. Dentomaxillofac Radiol. 2007; 36(1): 7-11.

13- Kaeppler G, Vogel A, Axmann-Krcmar D. Intra-oral storage phosphor and conventional radiography in the assessment of alveolar bone structures. Dentomaxillofac Radiol. 2000; 29(6): 362-7.

14- Kullendorff B, Petersson K, Rohlin M. Direct digital radiography for the detection of periapical bone lesions: a clinical study. Endod Dent Traumatol. 1997; 13(4): 183-9. 
15- Scaf G, Morihisa O, Loffredo Lde C. Comparison between inverted and unprocessed digitized radiographic imaging in periodontal bone loss measurements. J Appl Oral Sci. 2007; 15(6): 492-4.

16- Farhadi N, Shokraneh A, Mehdizadeh M. Effect of contrast inversion enhancement on the accuracy of endodontic file length determination in digital radiography. J Clin Diagn Res. 2015; 9(5): ZC102-5.

17- Kamburoğlu K, Murat S, Pehlivan SY. The effects of digital image enhancement on the detection of vertical root fracture. Dent Traumatol. 2010; 26(1): 47-51.

18- Akbari H. Comparison of the diagnostic accuracy of different image processing techniques for detection of bony lesions in indirect digital radiography [dissertation]. Ahvaz: Jundishapur University of Medical Sciences; 2016. [Persian]

19- Paurazas SB, Geist JR, Pink FE, Hoen MM, Steiman HR. Comparison of diagnostic accuracy of digital imaging by using CCD and CMOS-APS sensors with E-speed film in the detection of periapical bony lesions. Oral Surg Oral Med Oral Pathol Oral Radiol Endod. 2000; 89(3): 356-62. 